\title{
Antibiofilm Activity of Proteolytic Enzymes against Salmonella Gallinarum Isolates from Commercial Broiler Chickens
}

\author{
Iram Liaqat ${ }^{1 *}$, Tahir Hussain ${ }^{1,2}$, Aisha Waheed Qurashi' ${ }^{3}$, Gulbeena Saleem ${ }^{2}$, \\ Asia Bibi $^{4}$, Muhammad Fiaz Qamar ${ }^{5}$, Shaukat Ali ${ }^{1}$ and Ikram-ul-Haq ${ }^{6}$ \\ ${ }^{1}$ Microbiology Laboratory, Department of Zoology, Government College University, \\ Lahore, Pakistan \\ ${ }^{2}$ Department of Pathology, University of Veterinary and Animal Sciences, Lahore, \\ Pakistan \\ ${ }^{3}$ Department of Biology, Lahore Garrison University, Lahore, Pakistan \\ ${ }^{4}$ Department of Zoology, The Women University, Multan, Pakistan \\ ${ }^{5}$ Department of Pathobiology, University of Veterinary and Animal Sciences, Lahore \\ sub-campus Jhang, Pakistan \\ ${ }^{6}$ Institute of Industrial Biotechnology, GC University, Lahore-54000, Pakistan
}

\begin{abstract}
A B S T R A C T
Salmonella Gallinarum, is a host specific pathogenic bacterium of fowl typhoid, one of the most important diseases of poultry that increases the death rate and reduction in eggs production. Bacteria forms the complex structural colonies enclosed in a sticky matrix known as biofilm. Various antimicrobial approaches used to treat gastrointestinal infections are usually ineffective due to biofilm formation. The purpose of this study was to (1) compare biofilm formation of three $S$. Gallinarum strains isolated from commercial broiler chicken by three different methods i.e., congo red, test tube and air liquid interface coverslip, (2) biofilm quantification at different time intervals and (3) monitor antibiofilm effect of three proteolytic enzymes including trypsin, chymotrypsin and proteinase k against $S$. Gallinarum. We observed that $S$. Gallinarum has strong biofilm forming ability as observed by dark black colonies on congo red medium. Quantification assays such as test tubes revealed significantly $(\mathrm{p}<0.001)$ strong biofilm after 5 days with significantly increased planktonic cells (after 3 days) and increased loosely bound cells (after 5 days). Similarly, air liquid interface coverslip indicated significant increase in biofilm after 1 day. Comparison of antibiofilm effect using proteolytic enzymes indicated that although all enzymes resulted in significant decrease $(p<0.05)$ in biofilm formation after 1 hour, however, inhibitory effect of proteinase $\mathrm{k}$ was more pronounced ( $<0.001 ; 80 \%)$ compared to the other two enzymes ( $45 \%$ and $34 \%$ respectively). Hence, we concluded from this study, that $S$. Gallinarum is a strong biofilm former. Use of proteases can strongly inhibit biofilm formation in vitro and can be used as effective therapeutic approach to control fowl typhoid epidemic along with an antibiotic therapy. The future prospects of the current study may include the testing of these proteases in poultry feed to see their effect on $S$. Gallinarum pathogenesis in vivo.
\end{abstract}

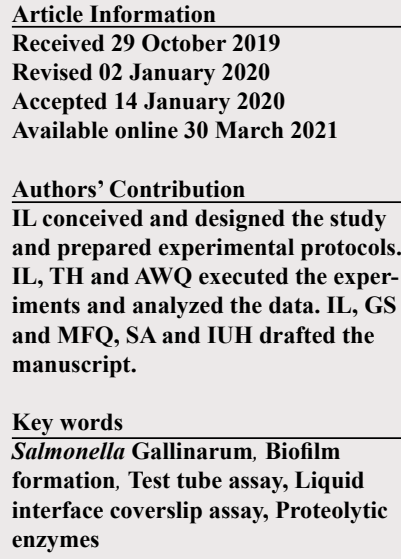

\section{INTRODUCTION}

$\mathrm{P}$ oultry sector has great economic importance in the developing countries like Pakistan. It has $10-12 \%$ population index growth and $40 \%$ share of meat in Pakistan (Hameed et al., 2017). Poultry industry is the source of employment for more than two million people in the country (Hussain et al., 2015). Salmonella is a facultative Gram negative anaerobe which belongs to Enterobacteriaceae family. Bacteria of this genus are motile

\footnotetext{
Corresponding author: iramliaq@hotmail.com 0030-9923/2021/0003-1111 \$ 9.00/0

Copyright 2021 Zoological Society of Pakistan
}

except for two serotypes, Salmonella Pullorum and Salmonella Gallinarum. S. Gallinarum causes a disease in chicken called as fowl typhoid (Revolledo, 2018). This septicemic disease causes high mortality as well as reduction in eggs production and responsible for great economic loss of $\$ 1.188$ billion to over $\$ 11.588$ billion per year (Wernicki et al., 2017). Mostly, the disease occurs in three weeks old birds that show clinical signs but the mortality increases through severe condition of old age birds. Signs of disease are anorexic condition, depression, ruffled feathers, dehydration and vent pasting (Dutta et al., 2015).

Salmonella produces thin aggregative fimbriae by virulent strains that are called curli which has a conclusive 
role in the formation of colony matrix. Additionally, cellulose produces the extra polymeric substance (EPS) that forms tightly packed covered cells in hydrophobic environment (Limoli et al., 2015), thus leading to biofilm formation. Other components of EPS are polysaccharides, proteins and nucleic acids (Liaqat et al., 2019).

Under field conditions, farmers use different types of antibiotics but bird's response to these antibiotic treatments remain limited due to biofilm formation. In biofilms, bacteria are firmly attached to the host and to each other. Their thick EPS and communication via quorum sensing (QS) make them highly resistant against antibiotics, harsh environmental conditions, disinfectants and host immune defensive mechanisms (Liaqat et al., 2014). Biofilm formation by Salmonella is the main cause of food contamination and poses main threat to safe transportation (Mukherji et al., 2015). Other important concern is dispersion of biofilm. Biofilm once established and mature, it does not remain as stationary, rather sloughs off old cells and each cell establish a new colony at site of adherence (Guilhen et al., 2017).

Proteolytic treatment of biofilm is a preferred approach due to proteinaceous contents of bacterial DNA and biofilm EPS. Among other enzymes, glycosidases and DNases have been used successfully to prevent biofilm formation or increasing its susceptibility to other effective antimicrobial agents (Liaqat et al., 2019). Proteolytic enzymes such as trypsin, chymotrypsin and proteinase $\mathrm{k}$ are reported to reduce the biofilm formation of many pathogenic strains and increase their susceptibility to conventional antimicrobial agents (Gilan and Sivan, 2013). Another important advantage is the intrinsic nature of few of these, since these are already present in human and animal body (duodenum), thus do not pose any significant pressure to host immune system (Boles and Horswill, 2008). This is an untapped area in $21^{\text {st }}$ century which needs further investigation. Various protease superfamilies have conserved catalytic mechanisms at kingdom level, but these are complex structures with different pockets in active pockets where potential drugs or cofactors bind. This means that these are distinct enough to offer selectivity for various antibiotics and bacterial inhibitors thus enhancing or limiting their potential activity in host (Culp and Wright, 2017).

In summary, developed countries have overcome the problem of fowl typhoid and other relevant diseases in poultry sector via national poultry improvement plan (NPIP) and the poultry health scheme. These programs ensure onsite biosecurity interventions to prevent or lessen recurrence of any previously known infection. Also, any newly occurring disease can likely be recognized immediately due to close veterinary surveillance.
However, various developing countries including Pakistan are adversely affected by fowl typhoid. This problem becomes worse, once the Salmonella strains stay in host for longer periods and establish biofilms. Every year, almost $80 \%$ of mortality occurs in affected birds of any age to date (Penha Filho et al., 2016). Hence, in the present study, biofilm formation and quantification of $S$. Gallinarum strains, previously isolated from commercial broiler chicks was investigated in vitro. We also performed series of experiments to understand the planktonic and loosely bound cells contents. Afterwards, antibiofilm potential of proteolytic enzymes (trypsin, chymotrypsin and proteinase $\mathrm{k}$ ) on biofilm, planktonic and loosely bound cells was studied.

\section{MATERIALS AND METHODS}

\section{Isolation and identification of S. Gallinarum}

Three isolates of $S$. Gallinarum (SG 119/Pak, SG 421/ India and SG 2a 189/China) were used in this study. These strains were previously isolated and identified through various biochemical tests and confirmed by $16 \mathrm{~s}$ rRNA DNA sequencing (Arslan, 2017). Stock cultures from (-80 C) were refreshed, and cross streaked to verify purification.

\section{Biofilm formation and quantification of S. Gallinarum strains}

Congo red assay, test tube and air liquid interface coverslip methods were used to determine and quantify the biofilm forming ability of $S$. Gallinarum strains (SG 119, SG 421 and SG 189) following method by Liaqat et al. (2009). Briefly, for congo red assay, three strains were streaked onto congo red media plates and incubated for 24 hours at $37^{\circ} \mathrm{C}$. Colony color, appearance/growth and thickness was observed to categorize biofilm as strong, moderate and weak (Amrutha et al., 2017).

For test tube method, nutrient broth was taken in borosilicate glass tubes, inoculated and incubated with three $S$. Gallinarum isolates (SG isolate 119/Pak, SG isolate $421 /$ India and SG 2 a isolate $189 /$ China) at $37^{\circ} \mathrm{C}$ for three, five and seven days. After three days of incubation, $1^{\text {st }}$ set of tubes were assessed for biofilm forming ability. Culture medium was decanted and washed with $0.85 \%$ saline solution. Test tubes were dried and $0.1 \%$ crystal violet $(\mathrm{CV})$ was added. Afterwards, $0.85 \%$ saline solution was used to wash the stained biofilm. Later, 33\% glacial acetic acid was added to solubilize biofilms and $\mathrm{OD}_{580}$ was measured using spectrophotometer. Similar procedure was repeated to assess biofilm formation in glass tubes at five and seven days. The experiment was run in triplicates.

Air liquid interface coverslip method is another reliable method for biofilm quantification (Liaqat et al., 2009). Briefly, nutrient broth was inoculated with three $S$. 
Gallinarum isolates, poured in Petri plates and coverslips were placed aseptically. Following incubation of one and two days, coverslips were removed and $0.1 \% \mathrm{CV}$ was added. Coverslips were washed with $0.85 \%$ saline and air dried. Rest of the procedure was same as mentioned above.

\section{Cell determination method for different residual cells (Planktonic and loosely attached cells)}

Using test tube assay, planktonic cells and loosely attached cells of $S$. Gallinarum isolates (S SG 119/Pak, SG 421/India and SG 2a 189/China) were determined (Liaqat et al., 2009). Briefly, S. Gallinarum isolates (SG 119/Pak, SG 421/India and SG 2a 189/China) were inoculated in nutrient broth in glass test tube and incubated at $37^{\circ} \mathrm{C}$ three, five and seven days. Following incubation, cultures were centrifuged at $10,000 \mathrm{rpm}$ for $5 \mathrm{~min}$. The pellet was dissolved in of distilled water and $0.1 \% \mathrm{CV}$ was added. Pellet was obtained by centrifugation and washed thrice with $0.85 \% \mathrm{NaCl}$ solution. Afterwards, glacial acetic acid was used to dissolve the washed pellet. Optical density $\left(\mathrm{OD}_{580}\right)$ was determined spectrophotometrically to determine the planktonic cells of $S$. Gallinarum.

After pouring the media, left over tubes were handled aseptically and washed twice with $0.85 \% \mathrm{NaCl}$ to remove any loosely attached cells. These cells were further centrifuged at 10,000 rpm for $3 \mathrm{~min}$. Pellet was stained with $0.1 \% \mathrm{CV}$ and washed again. Rest of the procedure was same as described above.

\section{Effect of proteinase $K$, trypsin and chymotrypsin on biofilm formation of S. Gallinarum}

Proteolytic enzymes including trypsin, chymotrypsin and proteinase $\mathrm{k}$ (Sigma-Aldrich) were used in this study. Minimum inhibitory concentrations (MIC) of trypsin, chymotrypsin and proteinase $\mathrm{k}$ were $4 \mu \mathrm{g} / \mathrm{ml}, 3$ $\mu \mathrm{g} / \mathrm{ml}$ and $2 \mu \mathrm{g} / \mathrm{ml}$ in planktonic cultures, respectively. These concentrations were determined in a preliminary experiment. Briefly, nutrient broth containing various concentrations of proteases was inoculated with bacterial cell (around $10^{6} \mathrm{CFUs} / \mathrm{ml}$ ) with positive and negative controls in 96 well microtiter plates for 1 hour. After incubation, MIC was considered as the lowest possible concentration with no growth. Among two tested concentrations ( 3 and $5 \times$ MIC), $5 \times$ MIC produced better results for biofilm inhibition and was used further to check antibiofilm potential of proteolytic enzymes. Briefly, three isolates were grown in test tubes for 5 days. 20 $\mu \mathrm{g} / \mathrm{ml}^{-1}$ trypsin, $15 \mu \mathrm{g} / \mathrm{ml}^{-1}$ chymotrypsin and $10 \mu \mathrm{g} / \mathrm{ml}^{-1}$ proteinase $\mathrm{k}$ were added in each set of test tubes, followed by incubation at $30^{\circ} \mathrm{C}$ for an hour. LB broth with bacterial inoculum and without any enzyme was used as negative control.
Planktonic, loosely attached and biofilm cells were quantified using CV staining method as described above. Additionally, six-fold serial dilutions of bacterial suspension from each of planktonic, loosely attached and biofilm cells was spread on L-agar plates and incubated at $37^{\circ} \mathrm{C}$ for 24 hours to determine the total viable cells (TVC). Experiment was run in triplicates and data was recorded as mean reduction in $\log \mathrm{cfu} / \mathrm{ml}$ following proteolytic treatment.

\section{Statistical analysis}

Data was presented as mean and standard error of measurement (sem). Using SPSS Version, 13.0), one-way analysis of variance (ANOVA) followed by a post hoc Tukey test and Student's t-test were applied to establish the level of significance $(\mathrm{P}<0.05)$.

\section{RESULTS}

Biofilm quantification through test tube and coverslip assays: Colony color, appearance/growth and thickness

Congo red assay used for monitoring biofilm forming ability indicated that all Salmonella isolates were biofilm formers phenotypically due to variations in dark color and thickness (Table I). SG 421/India was the strong biofilm former (dark black colony with thick growth), SG 2a 189/ China was moderate biofilm former (black colony with moderate thickness) while SG 119/Pak was good biofilm former (grayish black colony with weak thickness). Test tube assay for biofilm quantification indicated that all strains were strong biofilm formers (Fig. 1a). It was observed that bacteria started producing thick biofilm from 3 days onward, which continued for 5 days. Significantly strong biofilm $(\mathrm{P}<0.001)$ was produced after 5 days by all strains. After 7 days, biofilm either declines or levels off. Similar trend was observed for all tested strains. Among all the three isolates, SG 421/India was the most robust biofilm former compared to other two strains. Biofilm formation sequence was SG 421/India > SG 119/Pak > SG 2a 189/China (Fig. 1a)). Similar findings were observed by congo red assay also.

Air liquid interface coverslip assay indicated that all the three $S$. Gallinarum isolates produced maximum biofilm $(\mathrm{P}<0.05)$ on day 1 . Similar to the test tube findings, SG 421/India was observed to be the best biofilm producer compared to the other two strains. Among the other two strains, SG 119/Pak produced better biofilm compared to SG 2a 189/China (Fig. 1b).

\section{Planktonic and loosely attached cells determination}

Three S. Gallinarum isolates (SG 119/Pak, SG 421/ India and SG 2a 189/China) were studied to determine 
effect of abiotic surface on residual cells i.e. planktonic cells and loosely attached cells. Using CV staining method, it was observed that there was a significant increase in planktonic cells of all the three isolates after 2 days $(\mathrm{P}<0.001)$. In contrast, loosely attached cells showed a significant rise $(\mathrm{P}<0.001)$ after 03 days (Fig. 2).

Table I. Biofilm formation ability of $S$. Gallinarum strains (SG 119/Pak, SG 421/India and SG 2a 189/ China) on congo red medium. SG 421/Pak showed thick black growth as observed on left panel figure. Growth of SG 119/ India was relatively weak compared to SG 421/Pak but stronger than SG 2a 189/China.

\begin{tabular}{lll}
\hline \multicolumn{3}{l}{ S. Gallinarum strains } \\
\hline SG 119/Pak & SG 421/India & SG 2a 189/China \\
+++ & ++++ & ++ \\
\hline
\end{tabular}
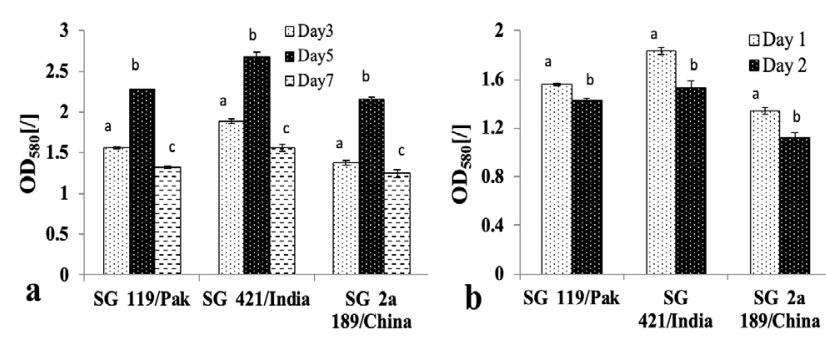

Fig. 1. Biofilm quantifications of $S$. Gallinarum strains (SG 119/Pak, SG 421/ India and SG 2a 189/China) using test tube and liquid interface coverslip assays. (a). Three strains were grown in test tubes over a time period of 3, 5 and 7 days. Each set was taken out after respectives time period and stained with $0.1 \% \mathrm{CV}$ stain. $\mathrm{OD}_{580}[/]$ was measured. (b). Three strains were grown on coverslips submerged in petriplates having nutrient broth. After day 1 and day 2, each of the respective set of coverslips was processed for biofilm quantification as mentioned in test tubes assay using $\mathrm{CV}$ staining method. Experiment was run in triplicates. One way ANOVA followed by post hoc Tukey test was used to analyze results in SPSS (Version 13.0). Bas with no common superscript are significantly different $(\mathrm{P}<0.05)$.

\section{Proteolytic treatment for biofilm inhibition}

Figure 3 represents the inhibitory effects of proteolytic enzymes on biofilm formation by all three isolates. A significant decrease $(\mathrm{P}<0.05)$ in biofilm formation of all isolates was observed compared to the control. Inhibitory effect of proteinase $\mathrm{k}$ was more pronounced $(80 \%$; $\mathrm{P}<0.001)$ compared to the treatment with trypsin and chymotrypsin (45 and 34\%), respectively. Regarding proteolytic effect of enzymes on planktonic and loosely attached cells, significant decrease in planktonic while non significant increase in loosely attached cells was observed after treatment with trypsin and chymotrypsin. However, proteinase $\mathrm{k}$ treatment led to significant decrease in planktonic cells and highly significant $(\mathrm{P}<0.001)$ increase in loosely attached cells (Fig. 4).

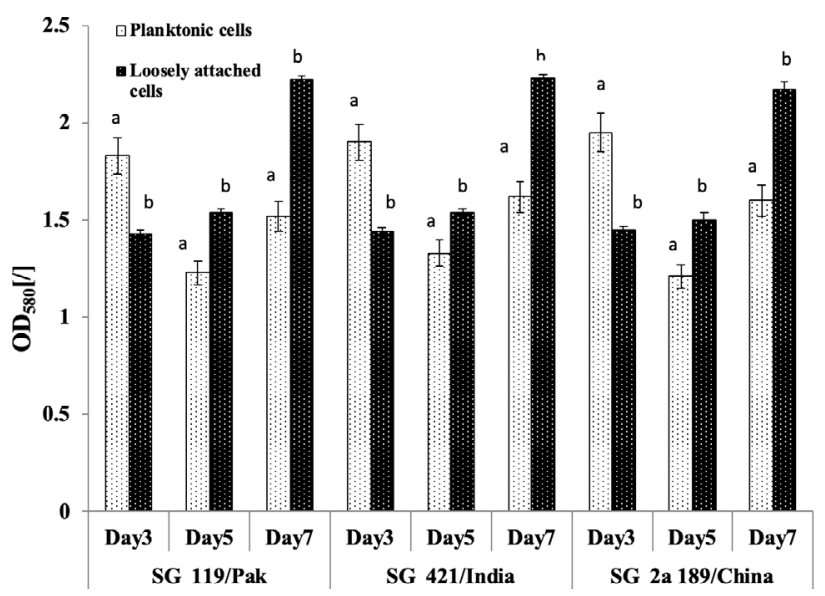

Fig. 2. Quantitative determination of planktonic and loosely attached cells of three $S$. Gallinarum strains (SG 119/ Pak, SG421/India and SG 2a 189/China) using test tube assay via CV staining method. Briefly bacteria were grown in test tubes for 3, 5 and 7 days. Each set was taken out after respectives time period, cells were centrifuges and stained with $0.1 \% \mathrm{CV}$ stain OD580 [/] was measured. Results are replica of three independent experiment. One way ANOVA followed by post hoc Tukey test was used to analyze results in SPSS (Version 13.0). Bars with no common superscript are significantly different $(\mathrm{p}<0.05)$.

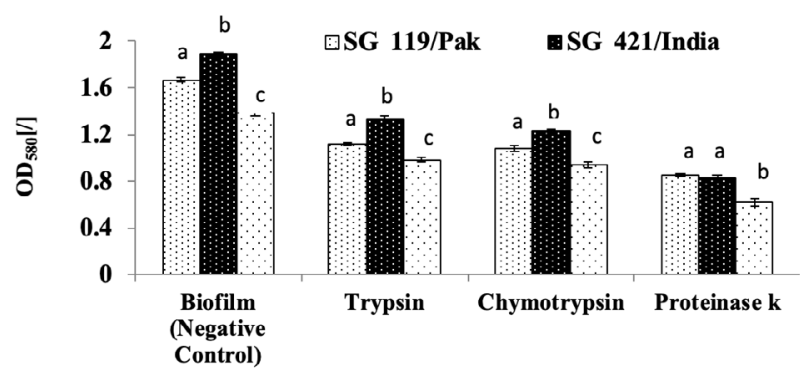

Fig. 3. Effect of proteolytic enzymes (trypsin, chymotrypsin and proteinase k) on biofilm formation of three $S$. Gallinarum strains (SG 119/ Pak, SG421/India and SG 2a 189/China) using test tube assay via $\mathrm{CV}$ staining method. Briefly bacteria were grown in test tubes. $30 \mathrm{mM}$ PBS containing 5 $\mathrm{X}$ MIC of trypsin, chymotrypsin and proteinase $\mathrm{k}$ was added in each set of test tubes respectively. CV staining method was used to determine inhibitory the effect of enzymes on biofilm. Results are replica of three independent experiment. One way ANOVA followed by post hoc Tukey test was used to analyze results in SPSS (Version 13.0). Bars with no common superscript are significantly different $(\mathrm{p}<0.05)$. 
Table II. Mean $\log$ reduction of cell viability after treatment with proteolytic enzymes bacterial strains.

\begin{tabular}{|c|c|c|c|}
\hline & \multicolumn{3}{|c|}{$\begin{array}{c}\log _{10} \text { cfu/ml control }-\log _{10} \text { cfu/ml with } \\
\text { proteolytic enzymes }\end{array}$} \\
\hline & Trypsin & Chymotrypsin & Proteinase $\mathbf{k}$ \\
\hline \multicolumn{4}{|c|}{ Planktonic Cells } \\
\hline SG 119 & $0.02 \pm 0.00$ & $0.02 \pm 0.00$ & $0.05 \pm 0.01$ \\
\hline SG 421 & $0.03 \pm 0.00$ & $0.03 \pm 0.00$ & $0.07 \pm 0.00$ \\
\hline SG 2a 189 & $0.03 \pm 0.00$ & $0.03 \pm 0.00$ & $0.06 \pm 0.00$ \\
\hline \multicolumn{4}{|c|}{ Loosely attached Cells } \\
\hline SG 119 & $0.03 \pm 0.00$ & $0.04 \pm 0.00$ & $0.03 \pm 0.00$ \\
\hline SG 421 & $0.03 \pm 0.00$ & $0.06 \pm 0.00$ & $0.04 \pm 0.00$ \\
\hline SG 2a 189 & $0.04 \pm 0.00$ & $0.05 \pm 0.00$ & $0.04 \pm 0.00$ \\
\hline \multicolumn{4}{|l|}{ Biofilm } \\
\hline SG 119 & $0.13 \pm 0.2$ & $0.21 \pm 0.04$ & $0.24 \pm 0.1$ \\
\hline SG 421 & $0.14 \pm 0.04$ & $0.19 \pm 0.00$ & $0.22 \pm 0.01$ \\
\hline SG 2a 189 & $0.12 \pm 0.03$ & $0.20 \pm 0.1$ & $0.21 \pm 0.01$ \\
\hline
\end{tabular}

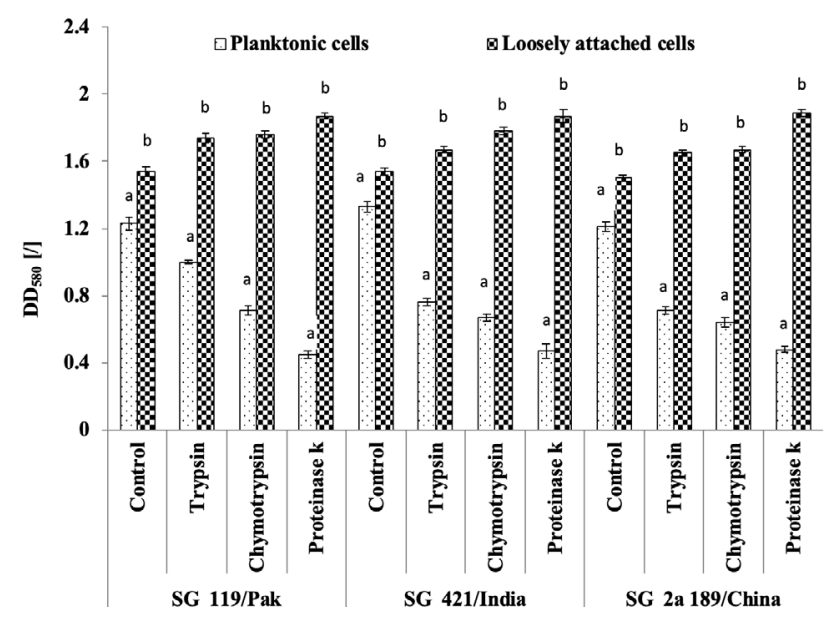

Fig. 4. Effect of proteolytic enzymes (trypsin, chymotrypsin and proteinase $\mathrm{k}$ ) on planktonic and loosely attached cells of three $S$. Gallinarum strains (SG 119/ Pak, SG421/India and SG 2a 189/China) using test tube assay via CV staining method. Briefly bacteria were grown in test tubes. $5 \mathrm{X}$ MIC of trypsin, chymotrypsin and proteinase $\mathrm{k}$ were added in each set of test tubes respectively. CV staining method was used to determine inhibitory the effect of enzymes on planktonic and loosely attached cells. Experiment was run in triplicates. One way ANOVA followed by post hoc Tukey test was used to analyze results in SPSS (Version 13.0). Bars with no common superscript are significantly different $(\mathrm{p}<0.05)$.

Data summarized in Table II shows the mean reduction in colony forming units (cfu) of planktonic, loosely attached and biofilm cells of three strains following treatment with proteolytic enzymes. However, Fig. IV showed significant increase in loosely attached cells via $\mathrm{CV}$ which might be due to the fact that $\mathrm{CV}$ can also bind with other biofilm components such as biofilm matrix, which also sloughs off along with loosely attached cells during detachment process. Compared to biofilm, planktonic and loosely bound cells of three strains were more susceptible to treatment by proteolytic enzymes. Non significant decrease in biofilm cells of all three strains (SG 119/Pak, SG 421/India and SG 2a 189/China), was observed following treatment with proteinase K (Table II).

\section{DISCUSSION}

Fowl typhoid is the chicken disease caused by $S$. Gallinarum and is of great public health concern. It results in great economic loss worldwide due to elevated mortality/morbidity of birds and is important to address in developing countries, particularly Pakistan (Batista et al., 2018). S. Gallinarum forms biofilms on host surface and exhibits high resistance against the treatment protocols of antibiotics and or vaccines (Mukherji et al., 2015). Little knowledge exists on biofilm formation and inhibition of $S$. Gallinarum, making prevention of disease a challenge in poultry sector. Additionally, no published data exists on inhibitory effect of proteases on biofilm formation by $\mathrm{S}$. Gallinarum to date. Hence, in this study, previously isolated $S$. Gallinarum strains were checked for biofilm forming ability phenotypically and quantitatively. Comparison of planktonic and loosely bound cells in relation to biofilm cells was determined. In the end, inhibitory effect of proteolytic enzymes on residual and biofilm cells was assessed.

In order to check the effect of proteolytic enzymes on biofilm formation, we first established the qualitative and quantitative assays. Congo red assay indicated strong significant ability of all $S$. Gallinarum strains. Using this assay, we characterized the strains as strong, moderate or good biofilm formers. The extents of biofilm formation and its differentiation as strong, moderate or good is an indicator of its pathogenicity in the host (Mohamed and Huang, 2007). But this technique is not always reliable for the quantification of formed biofilm (Mohamed et al., 2015). Therefore, test tube and coverslip assays were used for biofilm quantification using $\mathrm{CV}$ method due to its superiority (Sindhanai et al., 2016). We performed the test tube assays over 7 days and coverslips assay over 2 days. This time span was selected due to the fact that bacteria were grown in batch cultures and further longer time span may lead to compromised results due to nutrient depletion. Regarding biofilm formation using test tubes, all strains 
exhibited good biofilm forming frequency (80-90\%). This frequency is similar to our previous reports about biofilm isolates from dental and environmental settings (Liaqat et al., 2009). Regarding time kinetics of biofilm formation, we observed that bacteria formed climax biofilms by 5 days, afterwards a decline was observed in all bacterial biofilms. Our data is in agreement with Mitrofanova et al. (2017), who reported biofilm initiation after 4 days, reaching to climax by 7 days. This also explains our observation of increased planktonic cells by 5 days and decline by 7 days. Of note, these cells were now being recruited for biofilm formation. Previously, Bryers (2008) reported similar findings and reported that biofilm matures by consuming nutrients and recruiting planktonic cells. Likewise, Rabin et al. (2015), observed that once the primary biofilm layer is established, it will recruit the bacterial cells of similar species or different species from the surrounding bulk volume to the biofilm. Similarly, Dang and Lovell (2016) explained the role of three biofilm matrix proteins (RbmA, RbmC and Bap1) for biofilm structure and formation in $V$. cholera. Among these, Bap1 recruits planktonic cells to the surface, and contributes to biofilm adhesion. Additionally, it might be possible that bacteria have now started the secretion of EPS which makes the biofilm more robust and mature. Previously, Prakash et al. (2003) established mature biofilm in $S$. Gallinarum strains due EPS secretion. Consistently, decline or leveling off observed in biofilm of all $S$. Gallinarum strains after 5 days also testifies significantly increased loosely attached cells. It indicates that biofilm maturation has stopped and now it is entering into the dispersal phase. Additionally, lack of nutrients in batch cultures might lead to the detachments of biofilm cells, thus leading to increased loosely attached cells as observed previously by Liaqat et al. (2009).

Another major focus of the study was to determine the antibiofilm potential of three proteolytic enzymes (trypsin, chymotrypsin and proteinase $\mathrm{K}$ ) as well as their effect on residual cells using MIC approach. Although biofilm isolates have been reported to resistant mostly used antimicrobial agents, all of our tested enzymes significantly inhibited biofilm formation. This is not surprising. Randrianjatovo-Gbalou et al. (2017) reported that enzymatic lysis of biofilm EPS matrix is an ideal approach to destroy biofilms and EPS is proteinaceous in nature. It mainly provides strength as well as support not only during biofilm maturation but also maintenance. Another possibility is that enzymes might interfere with bacterial ribosomes, thus inhibiting growth and ultimately biofilm formation (Fonseca et al., 2004). Sharafutdinov et al. (2016) established that proteases inhibit biofilm both by hydrolysis of matrix proteins and adhesions. We already know that trypsin is proteolytic enzyme that reduces monolayer biofilm and is specific for the peptide bonds of lysine and arginine, while proteinase $\mathrm{K}$ cleaves the peptide bonds of aliphatic, aromatic, or hydrophobic amino acids (Chaignon et al., 2007). Chymotrypsin is a proteolytic and monomeric enzyme, present in the duodenum of human and animals. It disintegrate biofilm EPS (Gilan and Sivan, 2013). Our data also corroborate the findings by Boles and Horswill (2008) who observed that both trypsin and proteinase $\mathrm{k}$ efficiently removed the biofilm formation produced by some $S$. aureus strains. Additionally, our findings about proteinase $\mathrm{K}$ as more efficient biofilm inhibitor are corroborated with many previous published reports, where authors demonstrated strong biofilm dispersal ability of proteinase K particularly in other bacterial genera (Chaignon et al., 2007; Boles and Horswill, 2008; Varhimo et al., 2011).

To evaluate the effects of proteolytic enzymes on biofilm formation, quantification of their effect on planktonic and loosely attached cells was necessary. Significantly decreased planktonic cells following treatment with trypsin and chymotrypsin could be directly attributed to the fact that biofilm though decreased but still planktonic cells were housed in it. On the other hand, increased loosely attached cells indicated biofilm dispersal which was more vigorous, following treatment with proteinase $\mathrm{K}$. These findings are consistent with the previous study by McAuliffe et al. (2006), who observed exposure to oxytetracycline inhibits EPS production in Mycobacterium bovis biofilm and decreased planktonic cells.

In line with the antibiofilm effect of proteolytic enzymes, we determined the viable cell count using conventional plating cfu method. There was no significant difference in cell viability of planktonic and loosely attached cells following treatment with proteolytic enzymes. In biofilm mode, however proteinase $\mathrm{k}$ showed non significant reduction in cell viability compared to treatment with trypsin or chymotrypsin. These results corroborate our previous study where we observed that antibiotic treatment didn't affect the cfu of planktonic and loosely attached cells, however significantly decreased biofilm cfu after 120 hours (Liaqat et al., 2009).

\section{CONCLUSION}

This study concluded that $S$. Gallinarum strains are robust biofilm formers and among the three proteolytic enzymes, proteinase $\mathrm{K}$ has strong antibiofilm potential. Testing the inhibition potential of such proteolytic enzymes could be considered as promising therapeutic strategy for biofilm eradication and in particular destruction of biofilm EPS. These are safe and effective agents that may increase the susceptibility of conventional antimicrobial 
agents. However, in vivo trials of these enzymes in poultry feeds to control fowl typhoid warrant additional in depth investigations.

\section{Statement of conflict of interest}

Authors have declared no conflict of interests.

\section{REFERENCES}

Amrutha, B., Sundar, K. and Shetty, P.H., 2017. Study on E. coli and Salmonella biofilms from fresh fruits and vegetables. J. Fd. Sci. Technol., 54: 1091-1097. https://doi.org/10.1007/s13197-017-2555-2

Arslan. , M., Gulbeena, S., Raheela, A. and Hassam, A., 2017. Rfbs Gene based characterization and histopathological investigation of Salmonella enterica subspecies enterica serovar Gallinarum from commercial broiler of three districts of Punjab Province. 2971.

Baidamshina, D.R., Trizna, E.Y., Holyavka, M.G., Bogachev, M.I., Artyukhov, V.G., Akhatova, F.S., Rozhina, E.V., Fakhrullin, R.F. and Kayumov, A.R., 2017. Targeting microbial biofilms using Ficin, a nonspecific plant protease. [Sci. Rep., 7: 46068. https://doi.org/10.1038/srep46068

Batista, D.F.A., de Freitas Neto, O.C., de Almeida, A.M., Maboni, G., de Carvalho, T.F., de Carvalho, T.P., Barrow, P.A. and Junior, A.B. 2018. Evaluation of pathogenicity of Salmonella Gallinarum strains harbouring deletions in genes whose orthologues are conserved pseudogenes in S. Pullorum. PLoS One, 13: e0200585. https://doi.org/10.1371/ journal.pone.0200585

Boles, B.R. and Horswill, A.R., 2008. Agr-mediated dispersal of Staphylococcus aureus biofilms. PLoS Pathog., 4: e1000052. https://doi. org/10.1371/journal.ppat.1000052

Bryers, J.D., 2008. Medical biofilms. Biotechnol. Bioeng., 100: 1-18. https://doi.org/10.1002/ bit. 21838

Chaignon, P., Sadovskaya, I., Ragunah, C., Ramasubbu, N., Kaplan, J. and Jabbouri, S. 2007. Susceptibility of staphylococcal biofilms to enzymatic treatments depends on their chemical composition. Appl. Microbiol. Biotechnol., 75: 125-132. https://doi. org/10.1007/s00253-006-0790-y

Culp, E. and Wright, G.D., 2017. Bacterial proteases, untapped antimicrobial drug targets. J. Antibiot., 70: 366-377. https://doi.org/10.1038/ja.2016.138

Dang, H. and Lovell, C.R., 2016. Microbial surface colonization and biofilm development in marine environments. Microbiol. Mol. Biol. Rev., 80: 91-
138. https://doi.org/10.1128/MMBR.00037-15

Dutta, P., Borah, M., Gangil, R. and Singathia, R., 2015. Gross/histopathological impact of Salmonella Gallinarum isolated from layer chickens in Jaipur and their antibiogram assay. Int. J. Adv. Vet. Sci. Tech., 4: 153-159. https://doi.org/10.23953/cloud. ijavst. 179

Fonseca, A.P., Extremina, C., Fonseca, A.F. and Sousa, J.C., 2004. Effect of subinhibitory concentration of piperacillin/tazobactam on Pseudomonas aeruginosa. J. med. Microbiol., 53: 903-910. https://doi.org/10.1099/jmm.0.45637-0

Gilan, I. and Sivan, A., 2013. Effect of proteases on biofilm formation of the plastic-degrading actinomycete Rhodococcus ruber C208. FEMS Microbiol. Lett., 342: 18-23. https://doi. org/10.1111/1574-6968.12114

Guilhen, C., Forestier, C. and Balestrino, D., 2017. Biofilm dispersal: multiple elaborate strategies for dissemination of bacteria with unique properties. Mol. Microbiol., 105: 188-210.

Hameed, T., Asmat, T.M., Tariq, M.M., Bajwa, M.A., Rafeeq, M., Hilal, B., Attique, M.A. and Bokhari, F.A., 2017. Study on current status and future trends of commercial poultry production in Pakistan. Pure appl. Biol., 6: 190-196. https://doi.org/10.19045/ bspab.2017.60013

Hussain, J., Rabbani, I., Aslam, S. and Ahmad, H., 2015. An overview of poultry industry in Pakistan. Worlds Poult. Sci. J., 71: 689-700. https://doi. org/10.1017/S0043933915002366

Liaqat, I., Bachmann, R.T. and Edyvean, R.G., 2014. Type 2 quorum sensing monitoring, inhibition and biofilm formation in marine microrganisms. Curr. Microbiol., 68: 342-351. https://doi.org/10.1007/ s00284-013-0484-5

Liaqat, I., Liaqat, M., Tahir, H.M., Ali, N.M., Arshad, M. and Arshad, N., 2019. Motility effects biofilm formation in Pseudomonas aeruginosa and Enterobacter cloacae. Pak. J. Pharm. Sci., 32: 927933.

Liaqat, I., Sumbal, F. and Sabri,. AN. 2009. Tetracycline and chloramphenicol efficiency against selected biofilm forming bacteria. Curr. microbiol., 59: 212220. https://doi.org/10.1007/s00284-009-9424-9

Limoli, D.H., Jones, C.J. and Wozniak, D.J., 2015. Bacterial extracellular polysaccharides in biofilm formation and function. Microbiol. Spectr., 3: 1-2. https://doi.org/10.1128/microbiolspec.MB-00112014

McAuliffe, L., Ellis, R.J., Miles, K., Ayling, R.D. and Nicholas, R.A., 2006. Biofilm formation by 
mycoplasma species and its role in environmental persistence and survival. Microbiology, 152: 913922. https://doi.org/10.1099/mic.0.28604-0

Mitrofanova, O., Mardanova, A., Evtugyn, V., Bogomolnaya, L. and Sharipova, M., 2017. Effects of Bacillus serine proteases on the bacterial biofilms. Biomed. Res. Int., 2017: 1-10. https://doi. org/10.1155/2017/8525912

Mohamed, A., Rajaa, A.M., Khalid, Z., Fouad, M. and Naima, R., 2016. Comparison of three methods for the detection of biofilm formation by clinical isolates of Staphylococcus aureus isolated in Casablanca. Int. J. Sci. Res., 5: 1156-1159.

Mohamed, J.A. and Huang, D.B., 2007. Biofilm formation by enterococci. J. med. Microbiol., 56: 1581-1588. https://doi.org/10.1099/jmm.0.47331-0

Mukherji,. R, Patil, A. and Prabhune, A. 2015. Role of extracellular proteases in biofilm disruption of gram positive bacteria with special emphasis on Staphylococcus aureus biofilms. Enz. Eng., 4: 126. https://doi.org/10.4172/2329-6674.1000126

Penha Filho, R.A.C., Ferreira, J.C., Kanashiro, A.M.I., Darini, A.L.D.C. and Berchieri Junior, A., 2016. Antimicrobial susceptibility of Salmonella Gallinarum and Salmonella Pullorum isolated from ill poultry in Brazil. Cienc. Rural., 46: 513-518. https://doi.org/10.1590/0103-8478cr20150398

Prakash, B., Veeregowda, B.M. and Krishnappa, G. 2003. Biofilms: a survival strategy of bacteria. Curr. Sci., 85: 1299-1307.

Rabin, N., Zheng, Y., Opoku-Temeng, C., Du, Y., Bonsu, E. and Sintim, H.O., 2015. Biofilm formation mechanisms and targets for developing antibiofilm agents. Future Med. Chem., 7: 493-512. https://doi. org/10.4155/fmc. 15.6
Randrianjatovo-Gbalou, I., Rouquette, P., Lefebvre, D., Girbal-Neuhauser, E., Marcato-Romain, C. 2017. In situ analysis of Bacillus licheniformis biofilms: amyloid-like polymers and eDNA are involved in the adherence and aggregation of the extracellular matrix. J. appl. Microbiol., 122: 1262-1274. https:// doi.org/10.1111/jam.13423

Revolledo, L., 2018. Vaccines and vaccination against fowl typhoid and Pullorum disease: An overview and approaches in developing countries. J. appl. Poult. Res., 27: 279-291. https://doi.org/10.3382/ japr/pfx066

Sharafutdinov, I., Shigapova, Z., Baltin, M., Akhmetov, N., Bogachev, M. and Kayumov, A., 2016. HtrA protease from Bacillus subtilis suppresses the bacterial fouling of the rat skin injuries. Bionanoscience, $\mathbf{6}$ : 564-567. https://doi.org/10.1007/s12668-016-02812

Sindhanai, V., Avanthiga, S.S. and Suresh Chander, V.C. 2016. Antibiotic susceptibility pattern of biofilm forming and biofilm non forming enterococci species. IOSR J. dent. med. Sci., 15: 33-37.

Varhimo, E., Varmanen, P., Fallarero, A., Skogman, M., Pyörälä, S., Iivanainen, A., Sukura, A., Vuorela, P. and Savijoki, K. 2011. Alpha-and $\beta$-casein components of host milk induce biofilm formation in the mastitis bacterium Streptococcus uberis. Vet. Microbiol., 149: 381-389. https://doi. org/10.1016/j.vetmic.2010.11.010

Wernicki, A., Nowaczek, A. and Urban-Chmiel, R., 2017. Bacteriophage therapy to combat bacterial infections in poultry. Virol. J., 14: 179. https://doi. org/10.1186/s12985-017-0849-7 